\title{
Avaliação da mistura de cultivares de aveia preta (Avena strigosa Schreb) com azevém (Lolium multiflorum Lam.) sob pastejo
}

\author{
Evaluation of a mixture of black oats (Avena strigosa Schreb) cultivars with Italian ryegrass \\ (Lolium multiflorum Lam.) under grazing
}

\author{
Stefani Macari ${ }^{1}$ Marta Gomes da Rocha ${ }^{2}$ João Restle ${ }^{2}$ Alcides Pilau ${ }^{1}$ \\ Fabiana Kellermann de Freitas ${ }^{3}$ Fabio Pereira Neves $^{3}$
}

\section{RESUMO}

O experimento foi conduzido com objetivo de avaliar a produção de novilhas de corte em duas cultivares de aveia preta (Avena strigosa Schreb): “Comum" e "IAPAR 61" em mistura com azevém (Lolium multiflorum Lam.). Foram avaliadas a massa de forragem (MF), oferta de forragem (OF), taxa de acúmulo diário de matéria seca (TA), carga animal (CA), ganho médio diário (GMD), ganho de peso vivo por hectare (GPA), proteína bruta $(P B)$ e digestibilidade in vitro da matéria orgânica (DIVMO). As cultivares avaliadas não diferiram $(P>0,05)$ para TA, CA, GMD, GPA e PB. A DIVMO de IAPAR 61 manteve valores mais elevados durante um período mais prolongado da estação de crescimento da pastagem. A cultivar de aveia preta IAPAR 61 pode ser indicada para utilização sob pastejo no Estado do Rio Grande do Sul.

Palavras-chave: carga animal, ganho médio diário, pastejo contínuo.

\section{ABSTRACT}

This work aimed at evaluating the production of beef heifers in two cultivars of black oats (Avena strigosa Schreb): 'Comum' and 'IAPAR 61' mixed with Italian ryegrass (Lolium multiflorum Lam). The variables evaluated were: forage mass (FM), forage on offer (FO), daily accumulation of dry matter (FAD), stocking rate (SR), average daily gain ( $A D G)$, live weight gain (LWG), crude protein $(C P)$ and in vitro organic matter digestibility (IVOMD). No effects $(P>0.05)$ were detected on FAD, SR, DAP, LWG and CP for the two cultivars. The IVOMD of 'IAPAR 61' presented highest values during a more extended period in growing season of pasture. The 'IAPAR 61' cultivar can be indicated for use under grazing in Rio Grande do Sul State.
Key words: stocking rate, average daily gain, continuous grazing.

\section{INTRODUÇÃO}

O Rio Grande do Sul possui uma área potencial para plantio de aveia (Avena spp) de aproximadamente 4.900.000ha (IBGE, 2005). A aveia é uma das principais forrageiras utilizadas na formação de pastagens de inverno, cultivada de forma isolada ou consorciada com outras forrageiras de clima temperado, devido a sua alta produção de matéria seca e qualidade da forragem, resistência ao pisoteio e baixo custo de produção. A aveia preta (A. strigosa Schreb) destaca-se pela sua resistência à ferrugem e por produção de forragem de alta qualidade (FLOSS, 1988).

Em bovinocultura, entre as alternativas de alimentação para fêmeas de corte, com objetivo de redução de sua idade para o primeiro acasalamento, no Rio Grande do Sul, está o uso de misturas de gramíneas com crescimento inverno/primaveril, tais como a aveia e o azevém. Quando bem manejadas, elas asseguram níveis adequados de ganho de peso para os animais em pastejo.

Uma das dificuldades enfrentadas pelos agropecuaristas na implantação de sistemas de cultivo de inverno é a falta de cultivares alternativos aos já utilizados, com características desejáveis (HERLING

${ }^{1}$ Programa de Pós-graduação em Zootecnia, Universidade Federal de Santa Maria (UFSM), Santa Maria, RS, Brasil.

${ }^{2}$ Departamento Zootecnia, UFSM. Rua Tuiuti,1554/201, 97015-662, Santa Maria, RS, Brasil. E-mail: tata@via-rs.com.br. Autor para correspondência.

${ }^{3}$ Programa de Pós-graduação em Zootecnia, UFSM, Santa Maria, RS, Brasil. 
et al., 2001). No Rio Grande do Sul, há o uso quase exclusivo da cultivar "Comum" de aveia preta. Segundo NORO et al. (2003), a cultivar de aveia preta IAPAR 61 (A. strigosa Schreb. cv. IAPAR 61) é mais produtiva em relação à aveia preta "Comum” devido, principalmente, ao seu ciclo mais longo. Para a região Norte e Noroeste do Paraná, GRISE et al. (2002) evidenciaram o potencial da mistura de aveia preta IAPAR 61 e ervilha forrageira como alternativa para o periodo de escassez de forragem.

O presente trabalho foi conduzido com objetivo de avaliar características da pastagem e da produção animal em duas cultivares de aveia preta, “IAPAR 61" e "Comum”, em mistura com azevém, sob pastejo contínuo, usando novilhas de corte.

\section{MATERIAL E MÉTODOS}

O experimento foi realizado em área pertencente ao Departamento de Zootecnia da Universidade Federal de Santa Maria (UFSM), RS, no período de 08/05 a 02/11/2002. O solo da região é classificado como ARGISSOLO VERMELHO Distrófico arênico (EMBRAPA, 1999), pertencente à unidade de mapeamento São Pedro. O clima da região é Cfa (subtropical úmido), conforme classificação de Köppen (MORENO, 1961). A análise de solo da área experimental revelou os seguintes valores médios: $\mathrm{pH}-\mathrm{H}_{2} \mathrm{O}=5,4$; índice SMP = 5,6; argila $=260 \mathrm{~g} \mathrm{~kg}^{-1} ; \mathrm{P}=10,9 \mathrm{mg} \mathrm{L}^{-1} ; \mathrm{K}$ $=34,5 \mathrm{mg} \mathrm{L}^{-1} ; \mathrm{MO}=27 \mathrm{~g} \mathrm{~kg}^{-1} ; \mathrm{Al}=0,2 \mathrm{cmol}_{\mathrm{C}} \mathrm{L}^{-1} ; \mathrm{Ca}=$ $6,5 \mathrm{cmol}_{\mathrm{c}} \mathrm{L}^{-1} ; \mathrm{Mg}=2,8 \mathrm{cmol}_{\mathrm{c}} \mathrm{L}^{-1}$; saturação de bases = $70 \%$ e saturação de $\mathrm{Al}=3 \%$. Os dados médios mensais de temperatura e precipitação durante o período experimental foram tomados na Estação Meteorológica da UFSM.

A área experimental foi de 11,7ha, dividida em 12 potreiros, com área média de um hectare, mais uma área contígua de 4,6 ha para permanência dos animais reguladores. A pastagem foi implantada pelo sistema de preparo mínimo. A adubação de plantio foi de $300 \mathrm{~kg} \mathrm{ha}^{-1}$ da fórmula 5-20-20 (N-P-K). Os tratamentos foram duas cultivares de aveia preta (Avena strigosa), "Comum” e "IAPAR 61", utilizadas em mistura com azevém (Lolium multiflorum Lam.) cv. "Comum”. A densidade de semeadura foi 80 e $60 \mathrm{~kg} \mathrm{ha}^{-1}$ de sementes de “Comum” e "IAPAR 61", respectivamente, visando a assegurar uma população de 450 plantas $\mathrm{m}^{2-1}$ para ambas cultivares. Para o azevém, foram utilizados $35 \mathrm{~kg} \mathrm{ha}^{-1}$ de semente. Na adubação de cobertura, utilizou-se $135 \mathrm{~kg} \mathrm{ha}^{-1}$ de nitrogênio, na forma de uréia, divididos em três aplicações, nos dias 12/06, 10/08 e 25/09/2002.

Foram utilizadas novilhas da raça Charolês e suas cruzas com Nelore, com peso vivo e condição corporal, no início do pastejo, de $158 \mathrm{~kg}$ e 2,7, respectivamente. Foi utilizado sistema de pastejo contínuo, utilizando-se três novilhas teste e um número variável de reguladoras (MOTT \& LUCAS, 1952), para manter valores crescentes de massa de forragem no decorrer do ciclo da pastagem. A massa de forragem foi avaliada pelo método de dupla amostragem. A taxa de acúmulo diária de MS foi mensurada pela metodologia proposta por KLINGMAN et al. (1943), sendo utilizadas três gaiolas de exclusão por repetição.

Os animais em pastejo foram suplementados com grão de sorgo moído na proporção de $0,7 \%$ do peso vivo (PV), às 14h, diariamente.

A carga animal média por período foi calculada pelo somatório do peso médio de cada animal multiplicado pelo número de dias que este permaneceu na pastagem, dividido pelo número de dias do período. A oferta de forragem foi calculada pela razão entre a disponibilidade diária de forragem da pastagem pela carga animal utilizada em cada período de avaliação.

O ganho de peso médio diário (GMD) dos animais foi calculado pela seguinte fórmula: GMD = (PF-PI)/28, sendo PF o peso final, PI o peso inicial e 28 o número de dias do período. O ganho de peso vivo por área foi calculado através do somatório do ganho de peso dos animais teste mais o produto do GMD médio dos animais teste dividido pelo número de dias que cada animal regulador permaneceu no potreiro.

Para determinação dos parâmetros bromatológicos da forragem, foram utilizadas amostras coletadas através de simulação de pastejo (EUCLIDES et al., 1992), utilizando-se dois avaliadores treinados.

O teor de nitrogênio foi determinado pelo método de Kjeldahl (AOAC, 1984) para cálculo do teor de proteína bruta (PB) e a digestibilidade in vitro da matéria orgânica (DIVMO), conforme metodologia de TILLEY \& TERRY(1963).

O delineamento experimental usado foi o inteiramente casualizado, com parcelas subdivididas no tempo, com seis repetições de área. As variáveis estudadas foram submetidas à análise de variância e as médias comparadas pelo teste $\mathrm{F}$ ao nível de $5 \%$ de significância, bem como pela regressão. Quando detectada diferença entre as variáveis, foi realizada a comparação de médias pelo Teste Tukey no mesmo nível de significância. As análises foram realizadas pelo programa estatístico SAS versão 6.08 (1997). 


\section{RESULTADOS}

A tabela 1 mostra os valores de massa de forragem (MF), oferta de forragem (OF), taxa de acúmulo diário (TA), carga animal (CA), ganho médio diário (GMD) e ganho de peso por área (GPA) para as misturas testadas. Não houve interação entre tratamentos e períodos $(\mathrm{P}>0,05)$ para estes parâmetros avaliados e não houve diferença $(\mathrm{P}>0,05)$ entre as cultivares de aveia.

A MF aumentou no decorrer do ciclo das forrageiras, variando de 900 a $1500 \mathrm{~kg} \mathrm{ha}^{-1}$ de MS. A OF média manteve-se dentro da faixa ótima sugerida por MORAES (1991), de 8 a 10\% do PV, para obtenção de resultados satisfatórios em produção forrageira e animal, não sendo limitante ao consumo dos animais em pastejo.

Não houve diferença $(\mathrm{P}>0,05)$ para TA entre as cultivares de aveia, ocorrendo diferença apenas entre períodos, mostrando que ambas as cultivares responderam de maneira similar à precipitação, ao manejo da massa de forragem e à adubação nitrogenada, que são alguns dos fatores que interferem na TA. No ano do presente experimento (2002), ocorreu uma precipitação 82,7\% maior e uma insolação 14,8\% menor do que a média dos últimos 30 anos. Mesmo com estas adversidades, o valor médio da TA, 40 $\mathrm{kg} \mathrm{ha}^{-1}$ $\mathrm{dia}^{-1}$ de MS, foi semelhante a resultados encontrados

Tabela 1 - Massa e oferta de forragem, taxa de acúmulo de matéria seca, carga animal, ganho médio diário, ganho de peso por área das misturas de aveia preta comum mais azevém (“Comum”) e aveia preta cultivar IAPAR 61 mais azevém (“Comum”). Santa Maria, 2002 .

\begin{tabular}{|c|c|c|c|c|c|c|}
\hline \multirow{2}{*}{$\begin{array}{l}\text { Associação de azevém em } \\
\text { cultivares de aveia preta }\end{array}$} & \multicolumn{5}{|c|}{ Dias após o início da utilização da pastagem } & \multirow[b]{2}{*}{ Média } \\
\hline & $1-12$ & $13-40$ & $41-68$ & $69-96$ & $97-116$ & \\
\hline \multicolumn{7}{|c|}{ Massa de forragem (kg ha-1 de matéria seca (MS)) } \\
\hline Comum & 860,5 & 988,3 & 1066,5 & 1312,2 & 1561,3 & $1157,7^{*}$ \\
\hline IAPAR 61 & 778,3 & 966,0 & 1158,0 & 1407,3 & 1620,3 & 1185,9 \\
\hline Média & $819,4 d$ & $977,2 \mathrm{~cd}$ & $1112,2 \mathrm{c}$ & $1359,7 b$ & $1590,8 a$ & 1171,8 \\
\hline CV (\%) & 17,8 & 9,0 & 12,5 & 11,5 & 18,2 & \\
\hline \multicolumn{7}{|c|}{ Oferta de forragem (kg de matéria seca/100 kg de peso vivo (PV)) } \\
\hline Comum & 11,0 & 8,2 & 11,3 & 7,8 & 7,3 & $9,1^{*}$ \\
\hline IAPAR 61 & 11,6 & 9,0 & 10,2 & 7,0 & 8,0 & 9,1 \\
\hline Média & 11,3a & 8,6abc & $10,7 \mathrm{ab}$ & $7,4 \mathrm{C}$ & $7,6 \mathrm{bc}$ & 9,1 \\
\hline CV (\%) & 14,0 & 18,3 & 16,1 & 18,5 & 22,3 & \\
\hline \multicolumn{7}{|c|}{ Taxa de acúmulo de forragem $\left(\mathrm{kg}^{-1} \mathrm{ha}^{-1} \mathrm{dia}^{-1} \mathrm{MS}\right)$} \\
\hline Comum & 46,4 & 37,8 & 52,8 & 31,0 & 40,6 & $41,7^{*}$ \\
\hline IAPAR 61 & 41,3 & 35,6 & 54,6 & 26,6 & 34,5 & 38,5 \\
\hline Média & 43,6ab & $36,7 b$ & $53,7 \mathrm{a}$ & $28,8 b$ & 37,6ab & 40,1 \\
\hline CV (\%) & 22,8 & 14,7 & 15,9 & 31,9 & 38,4 & \\
\hline \multicolumn{7}{|c|}{ Carga animal (kg ha ${ }^{-1}$ de PV) } \\
\hline Comum & 710,4 & 679,0 & 711,7 & 940,5 & 929,6 & $794,2 *$ \\
\hline IAPAR 61 & 598,3 & 631,5 & 886,2 & 1117,10 & 967,9 & 840,2 \\
\hline Média & $654,3 b$ & 655,31b & 798,9ab & $1028,8 a$ & $948,7 \mathrm{a}$ & 817,2 \\
\hline CV (\%) & 3,1 & 5,7 & 23,5 & 20,6 & 13,0 & \\
\hline \multicolumn{7}{|c|}{ Ganho médio diário $\left(\mathrm{kg}^{-1}\right.$ dia $^{-1}$ animal $\left.{ }^{-1}\right)$} \\
\hline Comum & 0,767 & 0,881 & 0,990 & 0,874 & 0,648 & $0,832 *$ \\
\hline IAPAR 61 & 0,689 & 0,834 & 0,944 & 0,903 & 0,688 & 0,812 \\
\hline Média & $0,728 b c$ & 0,857abc & $0,967 a$ & 0,888ab & $0,668 c$ & 0,822 \\
\hline CV (\%) & 32,5 & 16,8 & 12,8 & 19,3 & 31,6 & \\
\hline \multicolumn{7}{|c|}{ Ganho de peso por área ( $\mathrm{kg} \mathrm{ha}^{-1}$ de PV) } \\
\hline Comum & 32,4 & 138,1 & 126,9 & 118,2 & 76,5 & $492,3 *$ \\
\hline IAPAR 61 & 27,0 & 117,8 & 124,1 & 148,4 & 80,8 & 498,3 \\
\hline Média & $29,7 \mathrm{c}$ & $127,9 a$ & $125,5 \mathrm{a}$ & 133,3a & $78,7 \mathrm{~b}$ & 495,3 \\
\hline CV (\%) & 37,9 & 28,6 & 24,3 & 41,5 & 29,3 & \\
\hline
\end{tabular}

Médias na linha seguidas por letras diferentes (a, b, c, d) diferem pelo teste Tukey $(\mathrm{P}<0,05)$.

* Diferenças não significativas $(\mathrm{P}>0,05)$.

Ciência Rural, v.36, n.3, mai-jun, 2006. 
por outros autores (FRIZZO et al., 2003), trabalhando na mesma área experimental. A produção total de forragem da mistura usando "Comum”, 5083,3kg ha"-1 de MS, não diferiu (P>0,05) de “IAPAR 61”, 4743,1kg ha $^{-1}$ de MS. Já NORO et al. (2003) encontraram produção total de MS maior para aveia preta cultivar "IAPAR 61", $7230 \mathrm{~kg} \mathrm{ha}^{-1}$ de MS, em relação à aveia preta "Comum”, $5280 \mathrm{~kg} \mathrm{ha}^{-1}$ de MS

Não houve diferença $(\mathrm{P}>0,05)$ para CA entre as cultivares de aveia com valores médios de 794,2 e 840,2kg ha-1 de PV para "Comum” e "IAPAR 61". O GMD proporcionado pelas duas cultivares de aveia foi igual a $0,823 \mathrm{~kg} \mathrm{ha}^{-1}(\mathrm{P}>0,05)$. Durante o decorrer do ciclo da pastagem, os ganhos foram inferiores nos períodos inicial e final devido ao baixo teor de MS no período inicial e na redução do valor nutritivo das forrageiras no final do seu ciclo. O valor médio de GMD dos animais no presente experimento foi superior ao encontrado por PRADO et al. (2003), 0,640 kg dia ${ }^{-1}$, trabalhando, com novilhos em pastagem de aveia preta “Comum”. Em pastagem de aveia preta "IAPAR 61" e ervilha forrageira (Pisum arvense L.), GRISE et al. (2002) observaram GMD de $1,017 \mathrm{~kg} \mathrm{dia}^{-1}$ para bezerros. Este maior ganho pode ser atribuído, em parte, à utilização de outra categoria animal, machos em pastejo, pois, conforme estes autores, a participação da leguminosa na mistura foi praticamente inexistente. Em Minas Gerais, CÓSER et al. (1984) obtiveram ganhos de peso por animal dia em torno de um quilograma em aveia, sob pastejo contínuo, usando bezerros mestiços leiteiros, por um período de 84 dias. A disponibilidade de forragem era em torno de $1700 \mathrm{~kg} \mathrm{ha}^{-1}$ de matéria seca.

Em pastagens de clima temperado, no Rio Grande do Sul, o GPA pode variar de 359,0kg (ROCHA et al., 2000) até 696,4kg de PV ha-1 (FRIZZO et al., 2000). O GPA está diretamente relacionado ao ganho médio diário e ao número de animais/dia/ha no período, sendo que estes são relacionados com a qualidade e produção de forragem. Os GPA obtidos no presente experimento, 492 e 498kg ha-1, respectivamente para "Comum” e "IAPAR 61", foram superiores aos 356kg ha-1 encontrados por GRISE et al. (2002), utilizando aveia preta “IAPAR 61" e ervilha forrageira.

Os valores de $\mathrm{PB}$ não diferiram entre cultivares $(\mathrm{P}>0,05)$, havendo diferença entre períodos $(\mathrm{P}<0,05)$, sendo a menor porcentagem de $\mathrm{PB}$ observada no último período. A redução dos teores de $\mathrm{PB}$, no final do ciclo da pastagem, é explicada pelo maior envelhecimento da forragem disponível, associado à maior fração de forragem senescente, maior proporção de colmos com considerável desenvolvimento de tecidos estruturais. Os teores médios de PB observados variaram de 14,6 a $24,7 \%$. Avaliando cultivares e linhagens de aveia, CECATO et al. (1998) obtiveram valor médio de 21\% de PB para a cultivar "IAPAR 61", e utilizando $100 \mathrm{~kg} \mathrm{ha}^{-1}$ de nitrogênio, CECATO et al. (2001) encontraram teor médio de 16,3\% de PB para a mesma cultivar, valor inferior à média de 19,9\% observada no presente trabalho, em "IAPAR 61" em mistura com azevém, com uso de $135 \mathrm{~kg} \mathrm{ha}^{-1}$ de nitrogênio.

Os valores de digestibilidade "in vitro" da matéria orgânica (DIVMO) são apresentados na figura 1. Houve interação entre tratamentos e períodos $(\mathrm{P}<0,05)$ para este parâmetro. A mistura de aveia “IAPAR 61" mais azevém apresentou um desenvolvimento quadrático (YI=78,76-0,53x+0,0026 $\mathrm{x}^{2}$ ), apresentando menor DIVMO no $101^{\circ}$ dia de pastejo $(\mathrm{P}<0,05)$, diferindo da mistura de aveia comum mais azevém, onde ocorreu um modelo cúbico (YC=90,11$\left.2,27 \mathrm{X}+0,037 \mathrm{x}^{2}-0,00018 \mathrm{x}^{3}\right)$, apresentando um decréscimo na DIVMO até o 46을 dia, aumentando até o 90ํ dia de pastejo. Maior digestibilidade pode estar associada à maior presença de perfilhos e folhas jovens (GRISE et al., 2001), assim a “IAPAR 61" provavelmente tenha apresentado estas características por um período mais prolongado de tempo do que a cultivar “Comum”. A manutenção de maiores valores de digestibilidade, por um período mais prolongado, observada em "IAPAR 61”, no entanto, não afetou os resultados obtidos em produção animal (Tabela 1). No presente trabalho, os animais apresentaram ganhos na faixa de $0,823 \mathrm{~kg}^{-1}$ $\mathrm{an}^{-1} \mathrm{dia}^{-1}$. Conforme BLASER et al. (1982), para ganhos na faixa de 0,750 a $1,1 \mathrm{~kg}^{-1} \mathrm{an}^{-1} \mathrm{dia}^{-1}$, para a categoria de novilhos, é necessário que a forragem apresente digestibilidade de 67 a $74 \%$, respectivamente. Valores acima de $80 \%$ de DIVMO foram encontrados por GRISE et al. (2001) em pastagem de aveia "IAPAR 61" mais ervilha forrageira.

\section{CONCLUSÕES}

A mistura de aveia preta cultivar "IAPAR 61” com azevém “Comum” apresenta características produtivas semelhantes à mistura da aveia preta cultivar “Comum” com azevém, podendo ser recomendada sua utilização para pastejo no Rio Grande do Sul. Com massa de forragem variando de 900 a $1500 \mathrm{~kg} \mathrm{ha}^{-1}$ de matéria seca e oferta de forragem de $10 \mathrm{~kg}$ de matéria seca para cada $100 \mathrm{~kg}$ de peso vivo, a carga animal, o ganho médio diário e o ganho de peso por área são semelhantes para as cultivares de aveias "Comum" e "IAPAR 61", quando associadas com azevém para pastejo. 


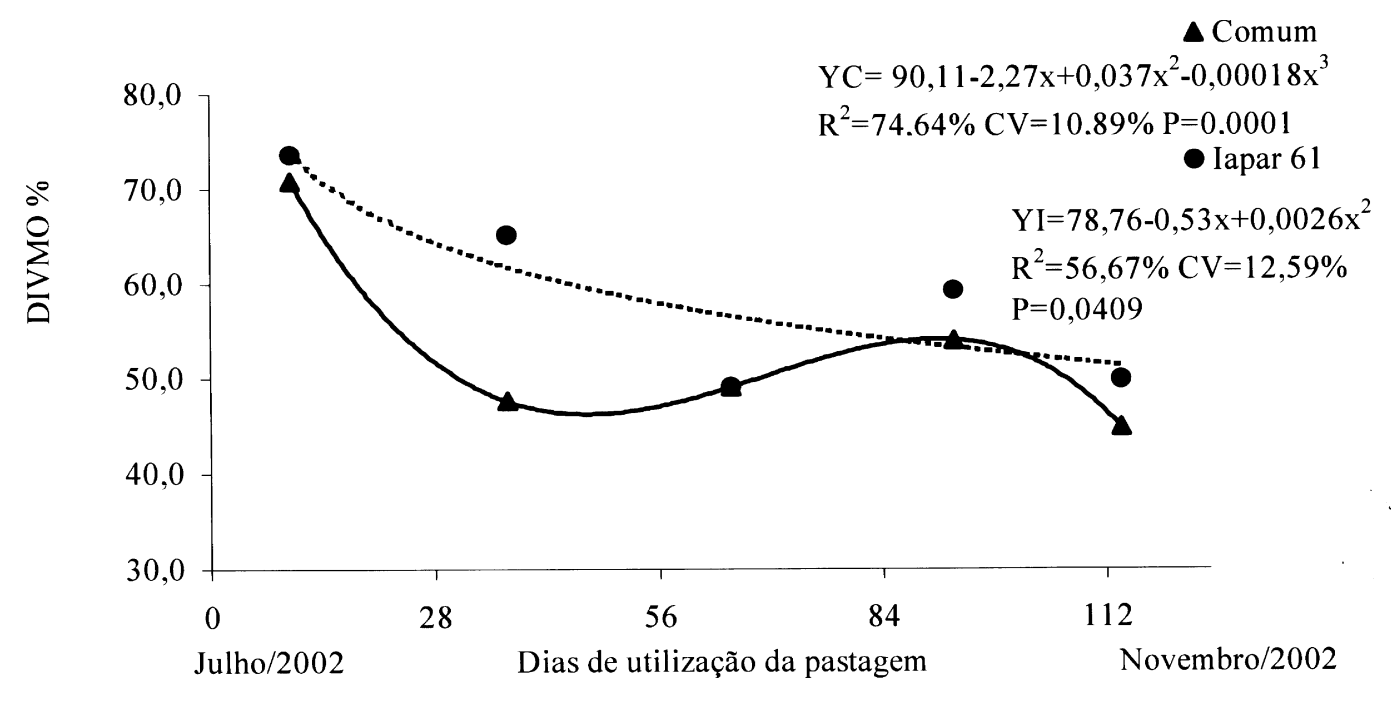

Figura 1- Digestibilidade da matéria orgânica (\%) das misturas de aveia preta comum com azevém (“Comum”) e aveia preta cultivar IAPAR 61 com azevém (“IAPAR 61”), utilizada sob pastejo para bovinos de corte. Santa Maria, 2002.

\section{REFERÊNCIAS}

ASSOCIATION OF OFFICIAL ANALYTICAL CHEMISTSAOAC. Official methods of analysis. 14ed. Washington, 1984. 1141p.

BLASER, R.E. Integrated pasture and animal management. Tropical Grasslands, v.16, n.9, p.9-24, 1982.

CECATO, U. et al. Avaliação de cultivares e linhagens de aveia (Avena spp). Acta Scientiarum, v.20, n.3, p.347-354, 1998.

CECATO, U. et al. Avaliação de aveia preta IAPAR 61 ("Avena strigosa" Schreb.) submetida a níveis crescentes de nitrogênio em área proveniente de cultura de soja. 2. composição química da planta. In: REUNIÃO ANUAL DA SOCIEDADE BRASILEIRA DE ZOOTECNIA, 38., 2001, Piracicaba. Anais... Piracicaba: SBZ Cappuradơd rom 21 junho de 2005.

COSER, A.C. et al. Desempenho de animais em aveia sob pastejo contínuo. O Produtor de Leite, v.15, n.85, p.22-26, 1984.

EMBRAPA. Centro Nacional de Pesquisa de Solos. Sistema brasileiro de classificação de solos. Brasília: EMBRAPARio de Janeiro, 1999. 412p.

EUCLIDES, V.P.B. et al. Avaliação de diferentes métodos de amostragem sob pastejo. Revista Brasileira de Zootecnia, v.21, n.4, p.691-702, 1992.

FRIZZO, A. et al. Produção de forragem e retorno econômico da pastagem de aveia e azevém sob pastejo com bezerras de corte submetidas a níveis de suplementação energética. Revista Brasileira de Zootecnia, v.32, n.3, p.632-642, 2003.

FRIZZO, A. et al. Efeito de diferentes níveis de suplementação energética no desempenho de bezerras em pastejo. In:
REUNIÃO ANUAL DA SOCIEDADE BRASILEIRA DE ZOOTECNIA, 37., 2000, Viçosa. Anais... Viçosa: SBZ, 2000. Cd-rom.

FLOSS, E.L. Manejo forrageiro da aveia (Avena spp) e azevém (Lolium spp). In: SIMPÓSIO SOBRE MANEJO DA PASTAGEM, 1988, Piracicaba. Anais... Piracicaba: FEALQ, 1988. p.231-268.

GRISE, M.M. et al. Avaliação do desempenho animal e do pasto na mistura aveia IAPAR 61 (Avena strigosa Schreb) e ervilha forrageira (Pisum arvense L.) manejada em diferentes alturas. Revista Brasileira de Zootecnia, v.31, n.3, p.10851091, 2002.

GRISE, M.M. et al. Avaliação da composição química e da digestibilidade "in vitro" da mistura aveia IAPAR 61 ("Avena strigosa" Schreb) + ervilha forrageira ("Pisum arvense" L.) em diferentes alturas sob pastejo. Revista Brasileira de Zootecnia, v.30, n.3, p.659-665, 2001.

HERLING, V.R. et al. Composição bromatológica de 17 cultivares de aveia (Avena spp.). In: REUNIÃO ANUAL DA SOCIEDADE BRASILEIRA DE ZOOTECNIA, 38., 2001, Piracicaba. Anais... Piracicaba: SBZ, 2001. Cd-rom.

Instituto Brasileiro de Geografia e Estatística (IBGE). Capturado em 21 junho de 2005. On line. Disponível em: www.sidra.ibge.gov.br/bda/agric.

KLINGLMANN, D.L. et al. The cage method for determining consumption and yield of pasture herbage. Journal of Society of Agronomy, v.35, p.739-746, 1943.

MORAES, A. Produtividade animal e dinâmica de uma pastagem de pangola ("Digitaria decumbens" Stent), azevém ("Lolium multiflorum" Lam) e trevo branco

Ciência Rural, v.36, n.3, mai-jun, 2006. 
(“Trifolium repens” L.) submetida a diferentes pressões de pastejo. 1991. 200f. Tese (Doutorado em Zootecnia) Universidade Federal do Rio Grande do Sul.

MORENO, J.A. Clima do Rio Grande do Sul. Porto Alegre: Secretaria da Agricultura, 1961. 41p.

MOTT, G.O.; LUCAS, H.L. The design, conduct, and interpretation of grazing trials in cultivated and improved pastures. In: INTERNATIONAL GRASSLAND CONGRESS, 6., 1952, State College. Proceedings... State College: Pennsylvania, State College, 1952. p.1380-1385.

NORO, G. et al. Gramíneas anuais de inverno para produção de forragem: avaliação preliminar de cultivares. Agrociência, v.7, n.1, p. 35-40, 2003.
PRADO, I.N. et al. Sistemas para crescimento e terminação de bovinos de corte a pasto: avaliação do desempenho animal e características da forragem. Revista Brasileira de Zootecnia, v.32, n.4, p. 955-965, 2003.

ROCHA, M.G. et al. Efeito da suplementação energética sobre a produção animal em pastagem cultivada de inverno. In: REUNIÂO ANUAL DA SOCIEDADE BRASILEIRA DE ZOOTECNIA, 37., 2000, Viçosa. Anais... Viçosa: SBZ, 2000. Cd-rom.

SAS Institute. Statistical analysis system user's guide. Version 6.08. Cary, 1997. 1014p.

TILLEY, J.M.A.; TERRY, R.A.A. Two stage technique for the "in vitro" digestion of forage crops. Journal of British Grassland Society, v.18, n.2, p.104-111, 1963. 